\title{
Solos de minas de scheelita como fontes de contaminação por metais pesados
}

\author{
Scheelite mines soils as sources of heavy metal contamination
}

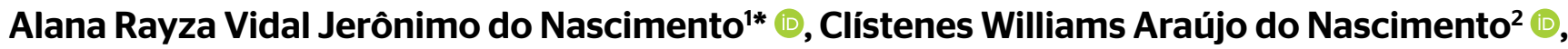
Karina Patrícia Vieira da Cunha' (1)
\end{abstract}

\begin{abstract}
RESUMO
O aporte de metais pesados é inerente à atividade de mineração, contudo a ausência de medidas de controle da poluição nas áreas mineradas concorre para a ampliação do potencial de contaminação do solo, da água e dos organismos. O objetivo deste trabalho foi avaliar o efeito do tempo de exposição de pilhas de estéril e rejeito que não atendem às medidas de proteção ambiental sob o estágio de contaminação do solo por metais pesados em minas de scheelita. Amostras de solo foram coletadas na camada de 0-20 cm em uma mina ativa e em uma mina desativada há quatro décadas. As amostras de solo foram submetidas às análises de granulometria, de pH e de teores dos metais pesados $\mathrm{Fe}, \mathrm{Mn}, \mathrm{Cr}$, Ni, Cd, Cu, Zn e Pb. Os incrementos nos teores de metais pesados em níveis similares nas minas ativa e desativada indicam que mesmo um menor tempo de exposição das pilhas de estéril e rejeito tem efeito prejudicial quando não são adotadas medidas de proteção e recuperação ambiental. Esses incrementos alertam para o risco de contaminação das áreas adjacentes às minas em decorrência de erosões tanto eólicas quanto hídricas durante os eventos chuvosos intermitentes característicos da região semiárida. Os teores de Cd, Cu e Pb superiores aos valores de investigação agrícola indicam que há risco à saúde humana e que é necessária a remediação das áreas mineradas.
\end{abstract}

Palavras-chave: mineração; qualidade do solo; rejeito; estéril.

\begin{abstract}
Heavy metals contribution is inherent to mining activity, however the absence of pollution control measures in mined areas contributes to the expansion of the contamination potential of soil, water, and organisms. The aim of this work was to evaluate the effect of exposure time of tailings and overburden deposition without environmental protection measures over soil heavy metal contamination stage in scheelite mines. Soil samples were obtained from $0-20 \mathrm{~cm}$ depth in active scheelite mine and in deactivated scheelite mine since four decades ago. Soil samples were submitted to analyses of particlesize, $\mathrm{pH}$ and contents of heavy metals $\mathrm{Fe}, \mathrm{Mn}, \mathrm{Cr}, \mathrm{Ni}, \mathrm{Cd}, \mathrm{Cu}, \mathrm{Zn}$, and $\mathrm{Pb}$. The increases of heavy metals contents at similar levels in active and deactivated mines indicate that even a smaller exposure time of overburden and tailings has a harmful effect when environmental protection and recovery measures were not adopted. These increases alert to the contamination risk of adjacent areas due to wind erosion and hydric erosion during the intermittent rainy events of semi-arid region. $\mathrm{Cd}, \mathrm{Cu}$, and $\mathrm{Pb}$ contents higher than values of agricultural investigation indicate that there is a risk to human health and that there is need for remediation of mined areas.
\end{abstract}

Keywords: mining, soil quality, tailings, overburden.

\section{INTRODUÇÃO}

A mineração eleva os teores de metais pesados no solo, tornando-se importante fonte de contaminação do ambiente. A extração e o beneficiamento do minério emitem poeiras e produzem água residuária e resíduos minerais que podem resultar em contaminação (LIU; PROBST; LIAO, 2005). Isso é ainda mais significativo quando, ao decorrer da exploração mineral, pilhas de estéril e rejeito são expostas à ação do vento e da água da chuva. Nesses casos, as pilhas atuam como fontes de difusão de metais pesados para o

solo e do solo para os demais componentes da bacia hidrográfica (PETTA et al., 2014).

A contaminação ocorre quando o teor de um elemento químico encontrado naturalmente é excedido após uma atividade antrópica. Ambientes contaminados apresentam restrições quanto ao uso e à ocupação atuais ou pretendidos. Os teores naturais de metais pesados no solo variam de acordo com a composição do material de origem, os processos pedogenéticos e o grau de desenvolvimento dos solos (BIONDI et al., 2011). Portanto, tais teores são estabelecidos regionalmente, 
compondo legislações específicas que são utilizadas como referência na caracterização da qualidade de um ambiente. Apesar de a contaminação restringir o uso dos recursos naturais, o alerta é acionado apenas quando o contaminante alcança concentrações elevadas e causa danos aos organismos vivos (MAIGA et al., 2005; PRUVOT et al., 2006). Nesses casos, o ambiente é considerado poluído, necessitando então do estabelecimento de medidas de remediação para a mitigação e o controle dos impactos causados no ecossistema.

É importante destacar que, diferentemente dos contaminantes orgânicos, os metais pesados não são modificados ou degradados química ou biologicamente, portanto, mesmo removendo-se a fonte contaminante, as concentrações de metais no solo persistem por muito tempo depois de sua entrada (GUO et al., 2006). Dessa forma, após o fechamento da mina, se nenhuma técnica de remediação for aplicada, aquele ambiente continua contaminado, e a longo prazo essa contaminação alcança áreas adjacentes.

Assim, o objetivo deste trabalho foi avaliar se diferentes tempos de exposição de pilhas de estéril e rejeito dispostas sem atender às medidas de proteção ambiental causam distinção sobre o estágio de contaminação do solo por metais pesados em minas de scheelita na região semiárida tropical.

\section{MATERIAIS E MÉTODOS}

\section{Área de estudo}

As minas subterrâneas de scheelita Barra Verde e Olho d’Água estão localizadas no município de Currais Novos (6¹5’39” Sul; 36³1’04” Oeste) no estado do Rio Grande do Norte (RN) (Figura 1). As minas estão inseridas na Província Scheelitífera do Seridó, que corresponde à maior concentração do mineral de tungstato de cálcio - scheelita $\left(\mathrm{CaWO}_{4}\right)-$ do Brasil (DANTAS, 2000). As atividades na mina Barra Verde iniciaram-se em 1947, foram interrompidas no fim da década de 1990, em virtude da queda do preço do minério no mercado internacional, e retornaram a partir de 2005 com a perspectiva de reaproveitamento da scheelita desperdiçada nas antigas pilhas de rejeito. A mina Olho d’Água foi desativada em 1976 após aproximadamente quatro décadas em atividade.

O clima da região é do tipo BSh (estepe) (KOTTEK et al., 2006), caracterizado por um regime de escassez e distribuição desigual de chuvas, com média pluviométrica de $610,5 \mathrm{~mm} /$ ano e período chuvoso entre os meses de fevereiro e abril. As formações vegetais incluem a caatinga hiperxerófila e a caatinga subdesértica do Seridó. Os solos predominantes na região são os neossolos litólicos (EMBRAPA, 1971; 2013).

A extração da scheelita é realizada, na mina Barra Verde, por meio da metodologia subterrânea de câmaras e pilares. O beneficiamento do mineral inclui as etapas de fragmentação (britagem e moagem) e concentração gravimétrica (jigue e mesas vibratórias) (Figura 2).
Coletaram-se amostras de solo em seis áreas mineradas e na área controle (Tabela 1). A seleção das áreas de amostragem tomou como base o tempo de exposição dos resíduos da mineração, bem como a presença ou não de vegetação.

\section{Amostragem do solo e análises}

Para as análises de atributos físicos e químicos, coletaram-se as amostras deformadas do solo na camada de $0-20 \mathrm{~cm}$ em cinco pontos amostrais simples em cada área selecionada para o estudo e descrita anteriormente. Misturaram-se as cinco amostras simples para formar uma amostra composta de aproximadamente $500 \mathrm{~g}$. Todo o procedimento foi repetido por três vezes visando à obtenção de três repetições para cada área selecionada. Cabe ressaltar que as áreas de amostragem eram pequenas, por isso a coleta de três amostras em cada área se mostrou satisfatória. As amostras coletadas foram secas ao ar, destorroadas e passadas em peneira de $2 \mathrm{~mm}$ de abertura de malha para obtenção da terra fina seca ao ar (TFSA), a qual foi submetida às análises laboratoriais.

Submeterem-se as amostras de solo às análises de granulometria pelo método do densímetro e diagrama triangular simplificado (EMBRAPA, 1997), de pH em água (1:2,5) (EMBRAPA, 1999) e dos teores dos metais pesados $\mathrm{Fe}, \mathrm{Mn}, \mathrm{Zn}, \mathrm{Cu}, \mathrm{Ni}, \mathrm{Cd}, \mathrm{Pb}$ e $\mathrm{Cr}$.

Para a análise dos teores dos metais pesados, passaram-se subamostras de solo em peneira de 100 mesh de abertura com malha inoxidável. As digestões das amostras ocorreram pelo método 3051A (USEPA, 1998). Nesse procedimento, a abertura das amostras foi realizada em sistema fechado por 12 minutos na rampa de temperatura, tempo necessário para atingir $180^{\circ} \mathrm{C}$, mantendo-se essa temperatura por mais 10 minutos. Em seguida, após resfriamento, verteram-se as amostras para balões de $50 \mathrm{~mL}$, sendo o volume dos balões preenchidos com água destilada. Realizou-se a leitura dos metais pesados no espectrofotômetro de absorção atômica. A qualidade das análises foi aferida pelo uso de spikes e de um material de referência (SRM 2709a San Joaquin Soil) com valores certificados para os metais; as recuperações variaram de 87 a $103 \%$.

Subamostras de $10 \mathrm{~cm}^{3}$ de solo também foram submetidas à análise utilizando-se o extrator Mehlich-1, para determinação dos teores disponíveis dos metais pesados (EMBRAPA, 1999).

\section{Análise e interpretação dos dados}

Os dados de granulometria, $\mathrm{pH}$ e teores dos metais pesados do solo de cada área de estudo submeteram-se à análise estatística descritiva e à correlação de Pearson. A correlação linear de Pearson procurou por relações existentes entre as respostas de granulometria, $\mathrm{pH}$ e metais pesados; as relações foram apresentadas quando ocorreram. A análise estatística descritiva e a correlação linear de Pearson utilizaram o software Statistica v.7. 
Os teores dos metais pesados $\mathrm{Zn}, \mathrm{Cu}, \mathrm{Ni}, \mathrm{Cd}, \mathrm{Pb}$ e Cr observados nas áreas em estudo foram comparados com os valores de prevenção (VP) e de investigação (VI), estabelecidos pela Resolução do Conselho Nacional do Meio Ambiente (CONAMA) nº 420/2009 (BRASIL, 2009), e também com os valores orientadores de referência de qualidade (VRQ) (PRESTON et al., 2014).
VP e VI correspondem, respectivamente, ao valor limite de determinada substância no solo que não afeta suas funções e à concentração limite de determinada substância no solo acima da qual existem riscos potenciais, diretos ou indiretos, à saúde humana. Ressalta-se que os VI são estabelecidos para três cenários: agrícola, residencial e industrial (Tabela 2).

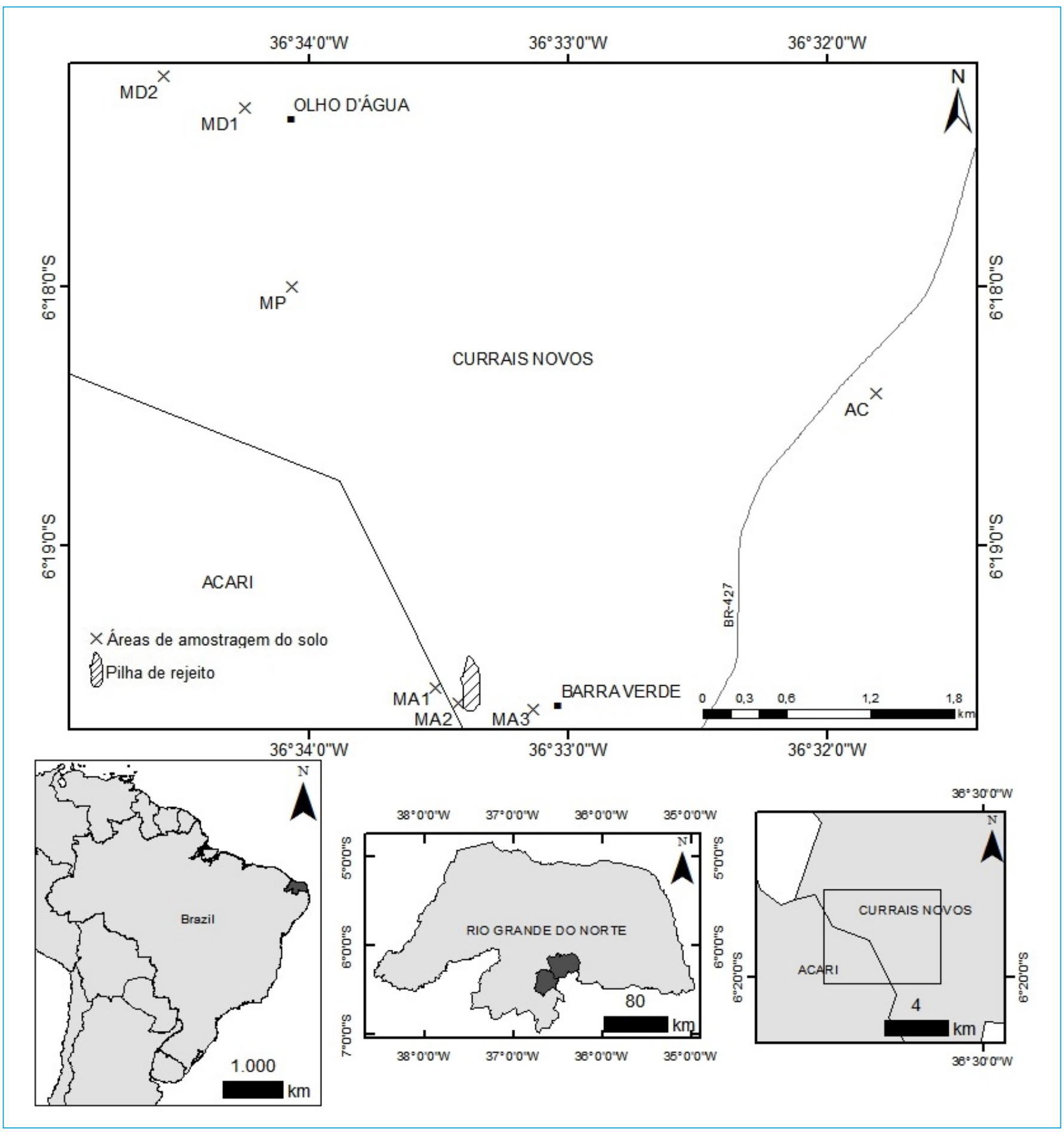

Figura 1 - Localização da área de estudo e das áreas de amostragem do solo nas minas Olho d’Água e Barra Verde, localizadas no município de Currais Novos (RN), semiárido brasileiro. 


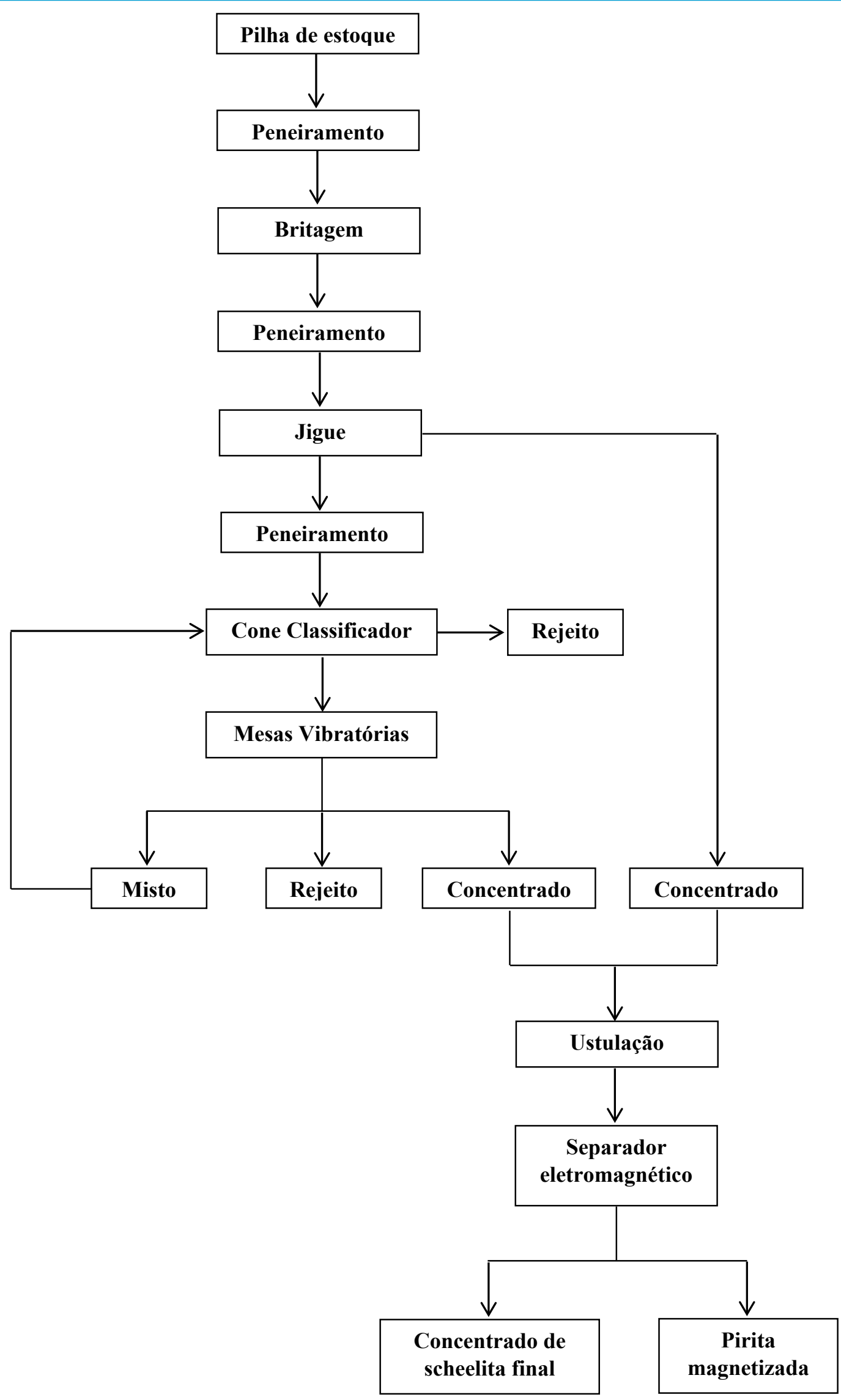

Figura 2 - Fluxograma simplificado das etapas de beneficiamento de scheelita na mina Barra Verde. 
A resolução supracitada também determina que cada estado da Federação estabeleça seus próprios VRQ em virtude das suas peculiaridades regionais. Embora os VRQ para o estado do RN ainda não tenham sido incorporados na legislação, recentemente foram determinados

Tabela 1 - Descrição das áreas de amostragem do solo nas áreas das minas Olho d’Água e Barra Verde e na área controle.

\begin{tabular}{|c|c|c|c|c|}
\hline Área & $\begin{array}{l}\text { Característi- } \\
\text { cas da área }\end{array}$ & $\begin{array}{l}\text { Tempo de } \\
\text { exposição }\end{array}$ & Manejo & Vegetação \\
\hline MP & $\begin{array}{c}\text { Abertura de } \\
\text { cava para } \\
\text { pesquisa } \\
\text { mineral }\end{array}$ & Recente & Nenhum & $\begin{array}{c}\text { Removida e } \\
\text { depositada sobre } \\
\text { o terreno }\end{array}$ \\
\hline MD1 & $\begin{array}{l}\text { Deposição } \\
\text { de rejeito }\end{array}$ & $\begin{array}{l}\text { Década de } \\
1970 \text { - atual }\end{array}$ & Nenhum & $\begin{array}{c}\text { Em } \\
\text { desenvolvimento } \\
\text { espontâneo }\end{array}$ \\
\hline MD2 & $\begin{array}{l}\text { Deposição } \\
\text { de estéril e } \\
\text { rejeito }\end{array}$ & $\begin{array}{l}\text { Década de } \\
1970 \text { - atual }\end{array}$ & Nenhum & $\begin{array}{c}\text { Em } \\
\text { desenvolvimento } \\
\text { espontâneo }\end{array}$ \\
\hline MA1 & $\begin{array}{l}\text { Deposição } \\
\text { de estéril }\end{array}$ & $\begin{array}{c}\text { Década de } \\
2000 \text { - atual }\end{array}$ & Nenhum & Esparsa \\
\hline MA2 & $\begin{array}{l}\text { Deposição } \\
\text { de rejeito }\end{array}$ & $\begin{array}{c}\text { Década de } \\
2000 \text { - atual }\end{array}$ & Nenhum & Ausente \\
\hline MA3 & $\begin{array}{l}\text { Próxima a } \\
\text { um curso } \\
\text { de água } \\
\text { residuária }\end{array}$ & $\begin{array}{c}\text { Década de } \\
2000 \text { - atual }\end{array}$ & Nenhum & Esparsa \\
\hline$A C$ & Mata nativa & - & $\begin{array}{c}\text { Pouca ou } \\
\text { nenhuma } \\
\text { interferência } \\
\text { antrópica }\end{array}$ & $\begin{array}{c}\text { Caatinga } \\
\text { hiperxerófila e } \\
\text { subdesértica }\end{array}$ \\
\hline
\end{tabular}

MP: mina em fase de pesquisa; MD1 e MD2: áreas da mina desativada Olho d'Água; MA1, MA2 e MA3: áreas da mina ativa Barra Verde; AC: área controle do solo.

Tabela 2 - Valores de prevenção (VP) e de investigação (VI) estabelecidos pela Resolução do Conselho Nacional do Meio Ambiente (CONAMA) no 420/2009.

\begin{tabular}{l|c|c|c|c}
\multirow{2}{*}{$\begin{array}{l}\text { Metal } \\
\text { Pesado }\end{array}$} & \multirow{2}{*}{ VP } & \multicolumn{3}{|c}{ VI } \\
\cline { 3 - 5 } & & Agrícola & Residencial & Industrial \\
\cline { 3 - 5 } $\mathrm{Zn}$ & 300 & 450 & 1.000 & 2.000 \\
\hline $\mathrm{Cu}$ & 60 & 200 & 400 & 600 \\
\hline $\mathrm{Ni}$ & 30 & 70 & 100 & 130 \\
\hline $\mathrm{Cd}$ & 1,3 & 3 & 8 & 20 \\
\hline $\mathrm{Pb}$ & 72 & 180 & 300 & 900 \\
\hline $\mathrm{Cr}$ & 75 & 150 & 300 & 400 \\
\hline
\end{tabular}

Fonte: adaptado de Brasil (2009). com base nos teores naturais dos metais $\mathrm{Ag}, \mathrm{Ba}, \mathrm{Cd}, \mathrm{Co}, \mathrm{Cr}, \mathrm{Cu}, \mathrm{Ni}$, $\mathrm{Pb}, \mathrm{Sb}, \mathrm{V}$ e Zn nos solos do estado (PRESTON et al., 2014) (Tabela 3). Para a determinação dos VRQ para o estado do RN, os autores coletaram amostras de solo em vários municípios potiguares, com algumas exceções, entre elas, o município de Currais Novos.

A análise de componentes principais (ACP) foi realizada com os dados de granulometria, $\mathrm{pH}$ e teores dos metais pesados utilizando-se o PC-ORD ${ }^{\circ}$ v.6 (MCCUNE; MEFFORD, 2011). A ACP teve por finalidade facilitar a interpretação dos resultados e observar se as interações entre metais pesados são distinguíveis entre as áreas selecionadas para o estudo.

\section{RESULTADOS E DISCUSSÃO}

Os solos das áreas mineradas em estudo apresentaram $\mathrm{pH}$ alcalino, enquanto na área controle (AC) o solo tem reação ácida (Tabela 4).

Os solos estudados demonstraram predominância da fração granulométrica areia, caracterizando a textura arenosa desses solos (Tabela 4). Os maiores teores de areia foram observados no solo da mina ativa em virtude da constante deposição de resíduos, com exceção da área próxima a um curso de água residuária da mina ativa Barra Verde (MA3), onde esse fluxo concorreu para um teor mais baixo de areia, bem como de argila.

De maneira geral, as áreas mineradas tiveram maiores teores de metais pesados $\mathrm{Fe}, \mathrm{Mn}, \mathrm{Cd}, \mathrm{Cr}, \mathrm{Cu}, \mathrm{Pb}$ e $\mathrm{Zn}$ em relação ao solo de $\mathrm{AC}$ (Figura 3). Apenas Ni apresentou teores inferiores ao de AC nas áreas de deposição de estéril (MA1) e de deposição de rejeito (MA2) da mina ativa Barra Verde.

Os teores de metais pesados no solo de AC estiveram próximos aos VRQ do estado do RN (Figura 3). Porém, os VRQ estabelecidos para $\mathrm{Zn}, \mathrm{Cu}, \mathrm{Ni}, \mathrm{Cd}, \mathrm{Pb}$ e Cr foram ultrapassados em pelo menos uma das áreas mineradas avaliadas no presente estudo, o que configura a contaminação do solo dessas áreas decorrente da atividade de mineração da scheelita. Cumpre ressaltar que Fe e Mn não estão incluídos na lista de elementos exigidos para a determinação dos VRQ, uma vez que são encontrados na constituição dos óxidos e, portanto, esperados naturalmente em teores elevados (DAVIES; MUNDALAMO, 2010). Os teores de Fe e Mn em AC foram inferiores aos determinados para o estado do $\mathrm{RN}$, os quais são iguais a, respectivamente, $27.997 \pm 660,44 \mathrm{mg} \cdot \mathrm{kg}^{-1}$ e 501,85 $\pm 8,34 \mathrm{mg} \cdot \mathrm{kg}^{-1}$ (PRESTON et al., 2014). Todavia, os incrementos nos teores de Fe e Mn nas áreas mineradas demonstram que a mineração da rocha contribui para o aporte desses elementos no solo.

Tabela 3 - Valores de referência de qualidade (VRQ) estabelecidos para o estado do Rio Grande do Norte.

\begin{tabular}{|c|c|c|c|c|c|c|c|c|c|c|c|}
\hline & $\mathrm{Ag}$ & $\mathrm{Ba}$ & $\mathrm{Cd}$ & Co & $\mathrm{Cr}$ & $\mathrm{Cu}$ & $\mathrm{Ni}$ & $\mathrm{Pb}$ & $\mathrm{Sb}$ & v & $\mathrm{Zn}$ \\
\hline & \multicolumn{11}{|c|}{$\mathrm{mg} \cdot \mathrm{kg}^{-1}$} \\
\hline VRQ & 0,88 & 58,91 & 0,10 & 15,41 & 30,94 & 13,69 & 19,84 & 16,18 & 0,18 & 28,71 & 23,85 \\
\hline
\end{tabular}

Fonte: adaptado de Preston et al. (2014). 
Os teores médios de $\mathrm{Cu}$ foram superiores ao VP nas áreas da mina ativa, ultrapassando também o VI agrícola em MA2. Os teores de Cd ultrapassaram o VP e o VI agrícola em todas as áreas mineradas e foram superiores ao VI residencial em MA2 (Figura 3). O teor de $\mathrm{Pb}$ também foi superior ao VI agrícola na área de deposição de estéril e rejeito da mina desativada Olho d’Água (MD2). Em contrapartida, os VP para Cr, Ni e Zn (BRASIL, 2009) não foram ultrapassados nas áreas mineradas, logo os teores desses metais no solo das áreas mineradas não são prejudiciais à sua qualidade e à saúde humana.

Tendo em vista que os teores de Cd excederam o VI agrícola, os solos das áreas mineradas estão incluídos na classe de qualidade do solo IV (BRASIL, 2009), o que significa que o órgão ambiental competente deverá instituir procedimentos e ações de gerenciamento de áreas contaminadas, que incluem a identificação das áreas suspeitas de contaminação, a elaboração da avaliação de risco e a execução das ações de controle para a eliminação do perigo ou redução, a níveis toleráveis, dos riscos identificados, bem como o monitoramento da eficácia das ações executadas.

A fragmentação das rochas, no beneficiamento do minério, favorece a separação dos grãos minerais antes coesos, atuando como o intemperismo físico. $\mathrm{Na}$ área de deposição de rejeito da mina desativada Olho d'Água (MD1), assim como nas áreas MD2, MA1 e MA2, as correlações positivas observadas entre os metais $\mathrm{Fe}, \mathrm{Mn}, \mathrm{Cd}, \mathrm{Cu}, \mathrm{Zn}$, $\mathrm{Pb}$ e o teor de areia (Tabela 5) revelam o caráter arenoso dos rejeitos e estéreis depositados nessas áreas e evidenciam a riqueza de minerais metálicos desses resíduos.

Em virtude desse caráter arenoso, os resíduos podem apresentar elevada erodibilidade. Assim, as áreas de deposição de resíduos podem atuar como fonte de metais pesados mediante o arraste direto por erosão das partículas de rejeito para as áreas adjacentes. Ademais, as características pluviométricas da região semiárida ampliam o potencial de contaminação tendo em vista que a ocorrência de eventos chuvosos concentrados em poucos dias do ano agrava o processo erosivo (NAVARRO et al., 2008). Na região semiárida da Espanha, as chuvas concentradas durante a curta estação chuvosa contribuíram para a dispersão dos metais pesados $\mathrm{Pb}, \mathrm{Zn}$, $\mathrm{Cu}$ e Cd pelos resíduos de minas abandonadas (NAVARRO et al., 2008). No distrito de mineração em Currais Novos, Cu e $\mathrm{Zn}$ foram emitidos pelas pilhas de rejeito descobertas, principalmente por processos eólicos e pelo transporte fluvial durante os eventos chuvosos intermitentes (PETTA et al., 2014).

$\mathrm{Na}$ área onde uma cava foi aberta para pesquisa mineral (MP), todos os metais apresentaram teores mais elevados que a AC (Figura 3), evidenciando a diversidade de minerais metálicos da rocha recém-explorada nessa área. Por sua vez, nas áreas da mina desativada (MD1 e MD2), os teores dos metais pesados superiores aos de AC são ainda mais preocupantes ao considerar o tempo de exposição das pilhas de rejeito e estéril sobre o solo desde o encerramento das atividades da mina, há cerca de 40 anos. Isso significa que essas áreas têm atuado como fonte de contaminantes ao longo de quatro décadas, revelando a dimensão do dano que o simples abandono de áreas mineradas pode impor ao ambiente. Na mina marroquina Kettara, abandonada desde 1981, os resíduos da mineração de ferro aportaram metais pesados principalmente por meio da erosão hídrica após eventos chuvosos, o que resultou na contaminação do solo evidenciada pelos teores de $\mathrm{Fe}, \mathrm{Cu}, \mathrm{Zn}, \mathrm{Pb}$ e As que excederam os valores de referências (KHALIL et al., 2013).

Tabela 5 - Correlações entre os teores dos metais pesados $\mathrm{Fe}, \mathrm{Mn}, \mathrm{Zn}, \mathrm{Cu}$ $\mathrm{Cd}$ e $\mathrm{Pb}$ e o teor de areia dos solos das minas Barra Verde e Olho d'Água.

\begin{tabular}{|c|c|c|c|c|}
\hline & MD1 & MD2 & MA1 & MA2 \\
\hline & \multicolumn{4}{|c|}{ Areia } \\
\hline $\mathrm{Fe}$ & 0,98 & 0,92 & ns & 0,94 \\
\hline $\mathrm{Mn}$ & 0,93 & 0,92 & 0,82 & 0,97 \\
\hline $\mathrm{Zn}$ & 0,98 & 0,85 & ns & 0,89 \\
\hline $\mathrm{Cu}$ & 0,98 & ns & ns & 0,96 \\
\hline $\mathrm{Cd}$ & 0,99 & 0,98 & 0,94 & 1,00 \\
\hline $\mathrm{Pb}$ & 0,95 & 0,98 & 0,92 & 0,92 \\
\hline
\end{tabular}

ns: valor de p não significativo a 5\% ( $p$ > 0,05); MD1 e MD2: áreas da mina desativada Olho d'Água; MA1 e MA2: áreas da mina ativa Barra Verde.

Tabela 4 - Média ( \pm desvio-padrão) do pH e granulometria dos solos das áreas das minas Barra Verde e Olho d’Água e da área controle (n=21).

\begin{tabular}{l|c|c|c|c|c|c}
\multirow{2}{*}{ Área } & Ph & Areia & Silte & \multicolumn{2}{|c}{ Argila } & Classificação textural \\
\cline { 2 - 6 } MP & & & g.kg ${ }^{-1}$ & \multicolumn{2}{|c}{ Franco arenosa } \\
\hline MD1 & $7,52 \pm 0,17$ & $530,33 \pm 12,86$ & $369,67 \pm 25,40$ & $100,00 \pm 20,00$ & Areia franca \\
\hline MD2 & $7,06 \pm 0,21$ & $790,33 \pm 13,28$ & $136,33 \pm 24,83$ & $73,33 \pm 11,55$ & Areia franca \\
\hline MA1 & $8,02 \pm 0,19$ & $843,67 \pm 58,48$ & $123,00 \pm 69,48$ & $33,33 \pm 11,55$ & Areia franca \\
\hline MA2 & $8,00 \pm 0,28$ & $867,67 \pm 69,29$ & $99,00 \pm 64,09$ & $33,33 \pm 23,09$ & Areia franca \\
\hline MA3 & $8,14 \pm 0,10$ & $864,00 \pm 48,88$ & $102,67 \pm 58,50$ & $33,33 \pm 11,55$ & Franco arenosa \\
\hline AC & $8,39 \pm 0,25$ & $642,67 \pm 346,14$ & $330,67 \pm 335,04$ & $26,67 \pm 11,55$ & Areia franca \\
\hline
\end{tabular}

MP: mina em fase de pesquisa; MD1 e MD2: áreas da mina desativada Olho d’Água; MA1, MA2 e MA3: áreas da mina ativa Barra Verde; AC: área controle do solo. 
A

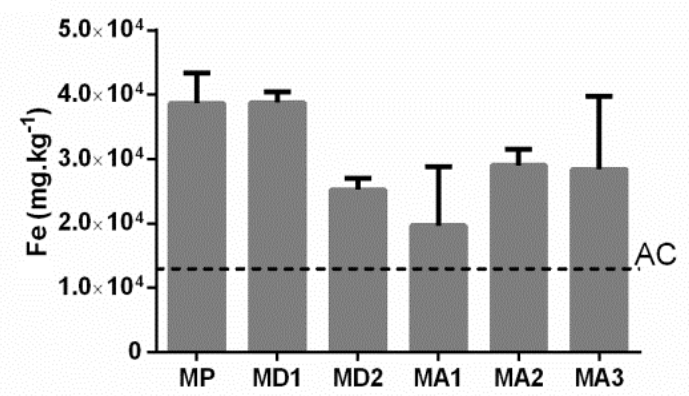

C

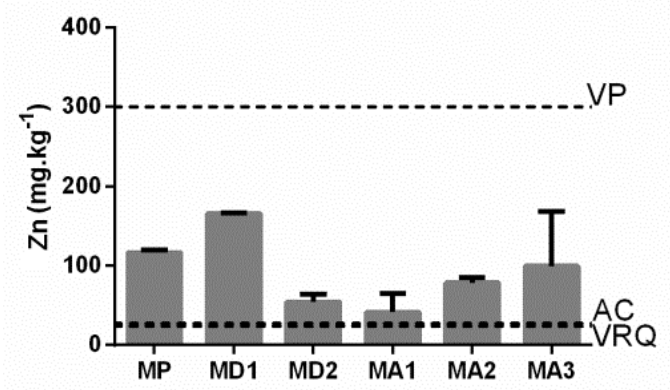

E

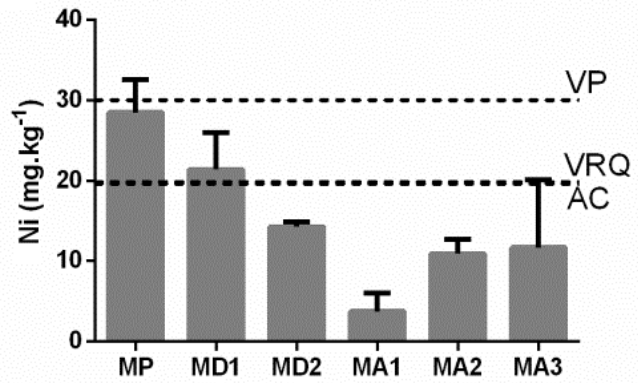

G

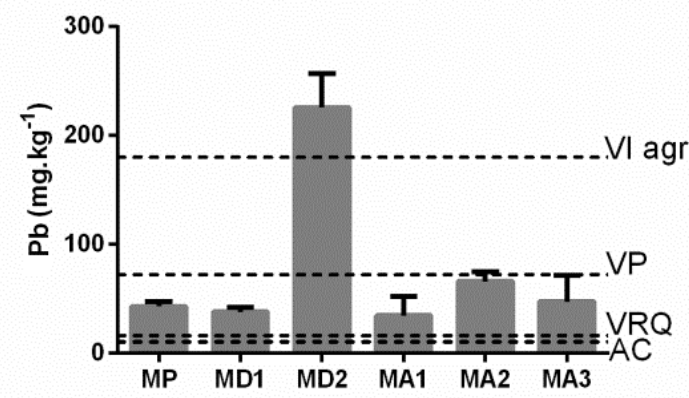

B

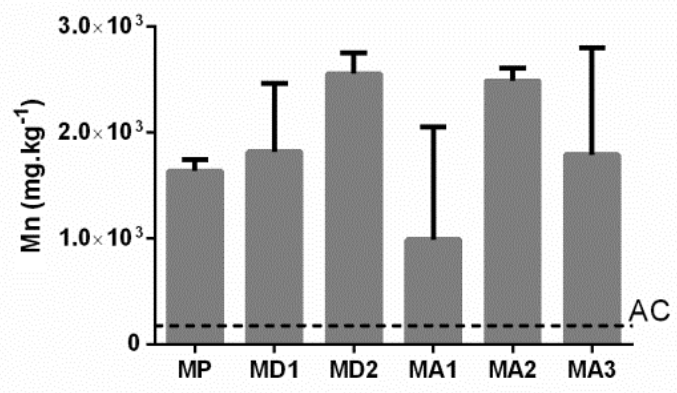

D

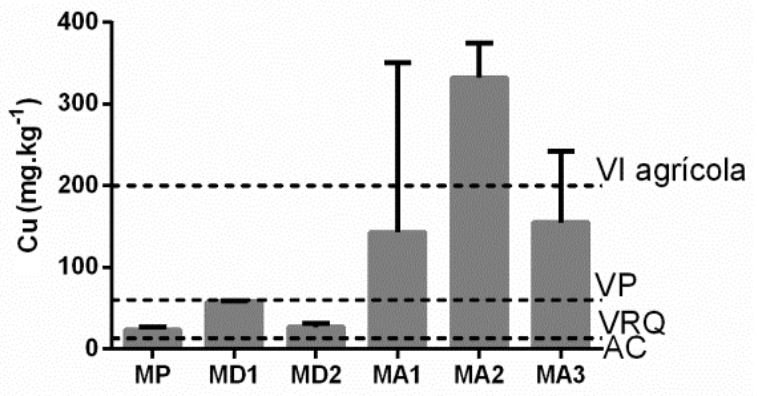

F

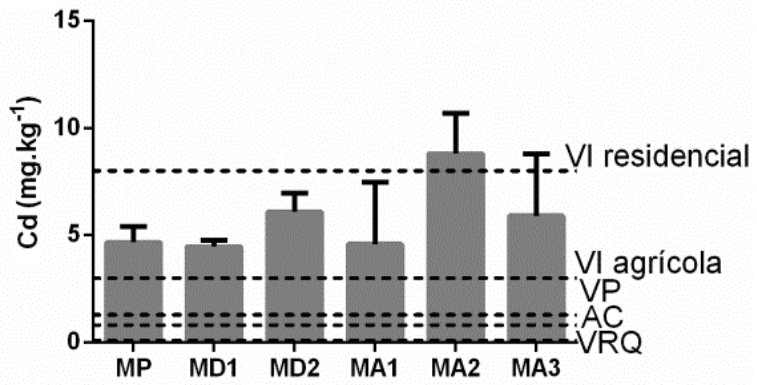

$\mathrm{H}$

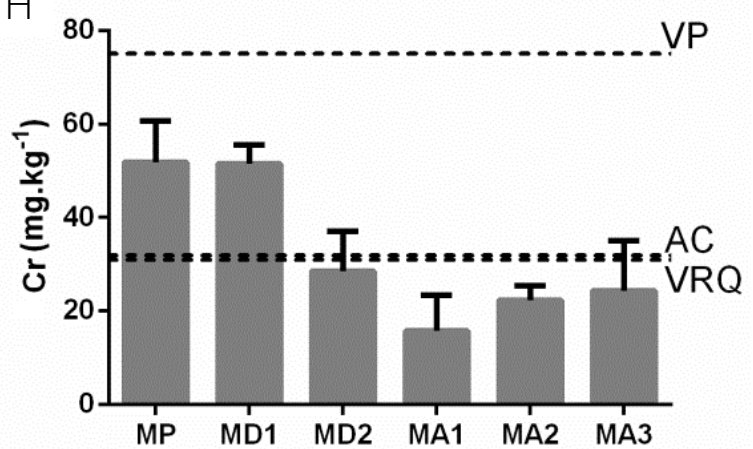

MP: mina em fase de pesquisa; MD1 e MD2: áreas da mina desativada Olho d’Água; MA1, MA2 e MA3: áreas da mina ativa Barra Verde; AC: área controle do solo; VRQ: valor de referência de qualidade; VP: valor de prevenção; VI: valor de investigação.

Figura 3 - Valores médios e desvios-padrão dos teores dos metais pesados $\mathrm{Fe}, \mathrm{Mn}, \mathrm{Zn}, \mathrm{Cu}, \mathrm{Ni}, \mathrm{Cd}, \mathrm{Pb}$ e $\mathrm{Cr}$ dos solos das áreas das minas Barra Verde e Olho d'Água e da área controle $(n=21)$. 
Apesar dos maiores teores de metais pesados nas áreas mineradas em relação à AC (Figura 3), os baixos teores disponíveis dos metais pesados evidenciam que os metais estão presentes em formas geoquímicas mais estáveis, porém ambientalmente disponíveis (Tabela 6). O caráter arenoso dos resíduos depositados nessas áreas sugere que os metais pesados estão predominantemente associados aos minerais primários. Enquanto o beneficiamento da scheelita concorre para a fragmentação dos minerais metálicos, a irregularidade das chuvas na região semiárida não favorece o intemperismo químico desses minerais, e, consequentemente, não favorece a presença de formas prontamente disponíveis

Tabela 6 - Teores disponíveis dos metais pesados $\mathrm{Fe}, \mathrm{Mn}, \mathrm{Cu}, \mathrm{Zn}, \mathrm{Cd}, \mathrm{Cr}$, Ni e Pb das áreas das minas Barra Verde e Olho d'Água e da área controle ( $\mathrm{n}=21$ ).

\begin{tabular}{|l|c|c|c|c|c|c|c|c|}
\multirow{2}{*}{ Área } & FeD & MnD & ZnD & CuD & NiD & CdD & PbD & CrD \\
\cline { 2 - 7 }
\end{tabular}
MP

\begin{tabular}{|c|c|c|c|c|c|c|c|c|}
\hline Média & 3,39 & 52,34 & 2,06 & 0,24 & 1,28 & 0,07 & 0,76 & 0,15 \\
\hline Desvio padrão & 1,26 & 16,48 & 0,76 & 0,02 & 0,25 & 0,02 & 0,28 & 0,02 \\
\hline Máximo & 4,65 & 63,00 & 2,53 & 0,25 & 1,46 & 0,09 & 1,09 & 0,17 \\
\hline Mínimo & 2,14 & 33,37 & 1,18 & 0,22 & 0,99 & 0,06 & 0,58 & 0,12 \\
\hline \multicolumn{9}{|l|}{ MD1 } \\
\hline Média & 13,16 & 27,02 & 2,31 & 0,92 & 0,48 & 0,01 & 0,57 & 0,10 \\
\hline Desvio padrão & 3,58 & 5,44 & 0,15 & 0,15 & 0,08 & 0,01 & 0,10 & 0,02 \\
\hline Máximo & 17,29 & 32,47 & 2,40 & 1,08 & 0,58 & 0,02 & 0,66 & 0,12 \\
\hline Mínimo & 10,90 & 21,60 & 2,14 & 0,78 & 0,42 & 0,01 & 0,46 & 0,08 \\
\hline \multicolumn{9}{|l|}{ MD2 } \\
\hline Média & 7,23 & 60,00 & 1,24 & 0,19 & 0,88 & 0,14 & 0,46 & 0,20 \\
\hline Desvio padrão & 0,41 & 9,82 & 0,83 & 0,02 & 0,13 & 0,02 & 0,41 & 0,05 \\
\hline Máximo & 7,69 & 70,97 & 2,18 & 0,22 & 1,01 & 0,16 & 0,89 & 0,21 \\
\hline Mínimo & 6,91 & 52,27 & 0,58 & 0,18 & 0,75 & 0,12 & 0,07 & 0,11 \\
\hline \multicolumn{9}{|l|}{ MA1 } \\
\hline Média & 9,19 & 21,05 & 0,99 & 0,44 & 0,56 & 0,07 & 0,25 & 0,46 \\
\hline Desvio padrão & 1,50 & 3,49 & 0,57 & 0,34 & 0,07 & 0,06 & 0,37 & 0,16 \\
\hline Máximo & 10,3 & 23,27 & 1,65 & 0,83 & 0,63 & 0,13 & 0,67 & 0,60 \\
\hline Mínimo & 7,48 & 17,02 & 0,64 & 0,24 & 0,49 & 0,01 & 0,00 & 0,29 \\
\hline \multicolumn{9}{|l|}{ MA2 } \\
\hline Média & 5,29 & 26,22 & 0,76 & 0,28 & 0,49 & 0,00 & 0,03 & 0,58 \\
\hline Desvio padrão & 2,01 & 2,05 & 0,23 & 0,08 & 0,06 & 0,01 & 0,05 & 0,06 \\
\hline Máximo & 7,56 & 27,80 & 0,95 & 0,37 & 0,55 & 0,01 & 0,08 & 0,64 \\
\hline Mínimo & 3,72 & 23,90 & 0,51 & 0,23 & 0,43 & 0,00 & 0,00 & 0,51 \\
\hline \multicolumn{9}{|l|}{ MA3 } \\
\hline Média & 6,11 & 45,50 & 1,05 & 0,70 & 0,52 & 0,04 & 0,33 & 0,46 \\
\hline Desvio padrão & 4,10 & 19,20 & 0,65 & 0,37 & 0,06 & 0,04 & 0,02 & 0,03 \\
\hline Máximo & 10,55 & 66,05 & 1,68 & 1,06 & 0,58 & 0,09 & 0,35 & 0,48 \\
\hline Mínimo & 2,47 & 28,02 & 0,39 & 0,32 & 0,47 & 0,00 & 0,31 & 0,43 \\
\hline \multicolumn{9}{|l|}{$A C$} \\
\hline Média & 36,58 & 40,40 & 1,39 & 0,24 & 0,27 & 0,03 & 0,20 & 0,06 \\
\hline Desvio padrão & 4,82 & 15,75 & 0,42 & 0,06 & 0,15 & 0,02 & 0,10 & 0,04 \\
\hline Máximo & 40,03 & 54,90 & 1,79 & 0,30 & 0,39 & 0,05 & 0,30 & 0,10 \\
\hline Mínimo & 31,07 & 23,65 & 0,95 & 0,18 & 0,10 & 0,00 & 0,11 & 0,03 \\
\hline
\end{tabular}

MP: mina em fase de pesquisa; MD1 e MD2: áreas da mina desativada Olho d’Água; MA1, MA2 e MA3: áreas da mina ativa Barra Verde; AC: área controle do solo. 
(solúvel e trocável) dos metais. Além disso, os metais pesados podem se tornar menos disponíveis em solos com pH alcalino (Tabela 4), pois essa condição favorece a formação de óxidos e hidróxidos insolúveis (SILVA; MENEZES, 2010).

$\mathrm{Na}$ Tabela 6, pode-se notar que, entre as áreas estudadas, o teor de FeD foi máximo em AC e mínimo em MP. Nas áreas mineradas, menores teores de $\mathrm{FeD}$ foram relacionados aos maiores valores de $\mathrm{pH}$ (Tabela 4). De fato, o pH exerce influência na disponibilidade de $\mathrm{Fe}^{2+}$, sendo este menos móvel em condições de pH elevado (CAMPOS, 2010). Essa relação pode ser demonstrada pelas correlações negativas entre FeD e pH em MP $(r=-0,88)$, MD2 $(r=-0,94)$, MA1 ( $r=$ $-0,92)$, MA2 $(r=-0,95)$ e MA3 $(r=-0,96)$. Por se tratar de um micronutriente, a redução da disponibilidade do Fe torna-se desfavorável para o crescimento das plantas, contudo, ao reduzir a disponibilidade de metais pesados, o aumento de $\mathrm{pH}$ reduz a contaminação ambiental (BARROS et al., 2011). O papel desempenhado pelo $\mathrm{pH}$ nas formas químicas dos metais pesados demonstrou-se em estudo realizado na mina espanhola Cabezo Rajao, onde não foi observada transferência de formas solúveis para corpos d'água adjacentes; a mobilização dos metais somente ocorreu em associação às partículas minerais (NAVARRO et al., 2008).

Apesar da disponibilização não ser favorecida nas condições de solo e clima da região semiárida, os maiores teores disponíveis dos metais pesados observados no solo das áreas mineradas em comparação à AC revelam a importância de evitar a exposição prolongada dos resíduos da mineração aos agentes intempéricos a fim de diminuir os riscos de contaminação do solo e dos demais componentes da bacia hidrográfica por metais pesados.

$\mathrm{Na}$ área recém-explorada $\mathrm{MP}$, os teores máximos de $\mathrm{ZnD}, \mathrm{NiD}$ e $\mathrm{PbD}$ (Tabela 6) reforçam a riqueza de minerais metálicos dos horizontes do solo escavado e depositado na superfície. Destaca-se que, enquanto $\mathrm{Pb}$ apresenta mobilidade reduzida em solos com $\mathrm{pH}$ alcalino pela formação de sais insolúveis, $\mathrm{Zn}$ pode apresentar mobilidade considerável pela solubilidade relativa dos complexos que podem se formar nesses solos (RAZO et al., 2004). Essa mobilidade do Zn aumenta o risco de contaminação dos corpos aquáticos adjacentes, visto que pode ser carreado por escoamento superficial nas enxurradas. Apesar de ser um elemento essencial ao crescimento e à manutenção dos organismos (MOURA et al., 2006), o Zn é tóxico para peixes e algas mesmo em baixas concentrações (BRASIL, 2005).

Os teores máximos de $\mathrm{MnD}$ e CdD em MD2 e de CuD em MD1 (Tabela 6) evidenciam que, ao longo dos anos, desde a desativação da mina, a atuação do intemperismo químico sobre os minerais primários das pilhas de estéril e rejeito tem resultado na disponibilização desses metais. Esses resultados são preocupantes em virtude do risco de contaminação não apenas do solo, mas também da vegetação que se desenvolveu nessas áreas. Cumpre salientar que a transferência de $\mathrm{Cd}$ do solo para o ambiente aquático não é muito eficiente, cerca de $94-96 \%$ do Cd permanece no solo (PEAKALL; BURGER, 2003). Essa característica do Cd é importante para a redução do risco de contaminação ambiental e deve incentivar a aplicação das técnicas de remediação. Por sua vez, o $\mathrm{Cu}$, assim como o $\mathrm{Zn}$, pode apresentar mobilidade considerável em solos com pH alcalino (RAZO et al., 2004) e também é tóxico para peixes e algas (BRASIL, 2005).

Os teores mínimos de $\mathrm{ZnD}, \mathrm{MnD}$, $\mathrm{CdD}$ e $\mathrm{PbD}$ observados nas áreas da mina ativa demonstram que o tempo de exposição dos resíduos, constantemente depositados, não foi longo o suficiente para favorecer a disponibilização desses metais pesados. Contudo, em MA2, observou-se o teor máximo de $\mathrm{CrD}$.

A ACP realizada para os teores de metais pesados explicou $77,67 \%$ da variabilidade dos dados nas duas primeiras componentes (Tabela 7)

Por meio da ACP, identificaram-se alguns grupos conforme a interação entre os teores totais dos metais pesados e as áreas selecionadas para o estudo: os solos das áreas AC e MA1 estão associados a menores teores dos metais pesados estudados; os solos das áreas MD1 e MP estão relacionados a maiores teores de Ni e Cr; e os solos das áreas MD2 e MA2 estão relacionados a maiores teores de $\mathrm{Cd}$ e Cu (Tabela 7 e Figura 4).

O plano definido pelas duas primeiras componentes principais (Tabela 7 e Figura 4) evidencia o enriquecimento das áreas mineradas por metais pesados decorrente do aporte desses elementos pelas pilhas estéril e rejeito depositadas nos solos sem medidas de contenção. De acordo com a ACP, MA1, entre as áreas mineradas, é a que

Tabela 7-Componentes principais extraídos da análise de componentes principais (ACP) para os teores de metais pesados com as respectivas cargas fatoriais, autovalores, variâncias total e acumulada e valor $p$.

\begin{tabular}{l|c|c|c}
\multirow{2}{*}{ Metal pesado } & \multicolumn{3}{|c}{ Componente principal } \\
\cline { 2 - 4 } & Componente 1 & Componente 2 & Componente 3 \\
\hline $\mathrm{Fe}$ & 0,94 & 0,19 & $-0,10$ \\
\hline $\mathrm{Mn}$ & 0,82 & $-0,49$ & 0,30 \\
\hline $\mathrm{Zn}$ & 0,85 & 0,30 & $-0,07$ \\
\hline $\mathrm{Cu}$ & 0,35 & $-0,73$ & $-0,52$ \\
\hline $\mathrm{Ni}$ & 0,49 & 0,76 & 0,14 \\
\hline Cd & 0,68 & $-0,70$ & $-0,06$ \\
\hline Pb & 0,26 & $-0,42$ & 0,86 \\
\hline Cr & 0,59 & 0,74 & 0,05 \\
\hline Autovalor & 3,53 & 2,69 & 1,16 \\
\hline Variância total (\%) & 44,07 & 33,60 & 14,51 \\
\hline Variância & 44,07 & 77,67 & 92,18 \\
\hline acumulada (\%) & 0,001 & 0,001 & 0,852 \\
\hline valor p & &
\end{tabular}

*Foram consideradas significativas as cargas fatoriais $>0,70$. 
apresenta menor potencial de atuar como fonte de teores de metais pesados para as áreas adjacentes.

A ACP dos teores disponíveis dos metais pesados e dos atributos físicos e químicos explicou $74,8 \%$ da variabilidade dos dados nas três primeiras componentes (Tabela 8).

Pela ACP, identificaram-se alguns grupos conforme a interação entre as áreas e os atributos selecionados para o estudo: os solos das áreas AC e MD1 estão associados a maiores teores de FeD e argila; os solos das áreas MA1 e MA2 estão relacionados a maiores teores de CrD; e os solos das áreas MP e MD2 estão relacionados a maiores teores de NiD (Tabela 8 e Figura 5).

A ACP dos teores disponíveis dos metais pesados revelou que a disponibilização de $\mathrm{Cr}$ aumentou com o $\mathrm{pH}$, ao contrário do que ocorreu para $\mathrm{Zn}, \mathrm{Pb}$ e $\mathrm{Mn}$, e os teores disponíveis de $\mathrm{Ni}$ e Cd diminuíram com o aumento do teor de areia (Figura 5), indicando que a textura arenosa favorece a perda desses metais em solução do solo por escoamento superficial. Os incrementos nos teores totais dos metais pesados em MP (Figura 3) resultaram na disponibilização de Ni nessa área.

Os resultados do presente estudo demonstram que os resíduos depositados nos solos das minas ativa e desativada, sem as devidas medidas de controle da poluição, são fontes potenciais de contaminação por metais pesados não apenas do solo, mas de toda a bacia hidrográfica. Entre as medidas cabíveis para impedir o aporte de metais pesados, destaca-se a contenção das pilhas de rejeito conforme os critérios preconizados na Norma Brasileira (NBR) 13028:2006 (ABNT, 2006).

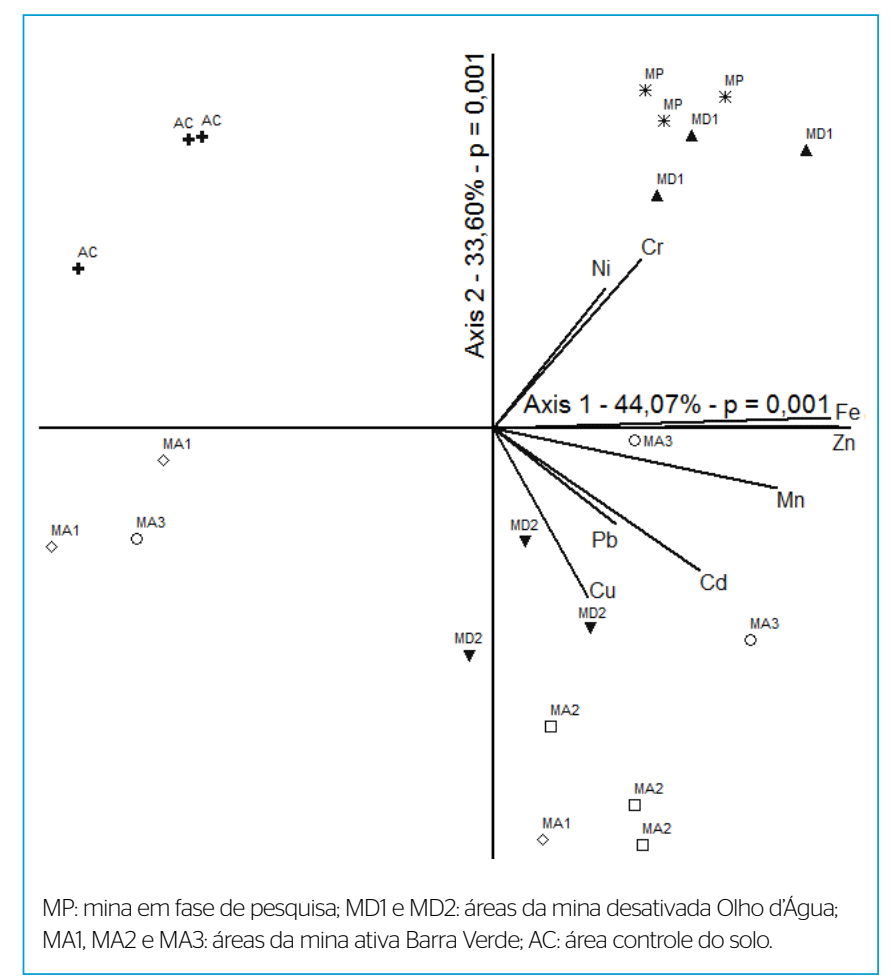

Figura 4 - Análise de componentes principais (ACP) dos teores dos metais pesados $\mathrm{Fe}, \mathrm{Mn}, \mathrm{Zn}, \mathrm{Cu}, \mathrm{Ni}, \mathrm{Cd}, \mathrm{Pb}$ e $\mathrm{Cr}$ dos solos das áreas das minas Barra Verde e Olho d'Água e da área controle $(n=21)$.
Tabela 8 - Componentes principais extraídas da análise de componentes principais (ACP) para $\mathrm{pH}$, teores de areia, silte e argila e teores disponíveis de metais pesados com as respectivas cargas fatoriais, autovalores, variâncias total e acumulada e p-valor.

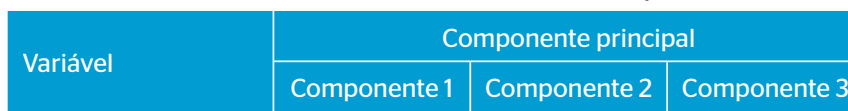

\begin{tabular}{l|c|c|c} 
& \multicolumn{3}{|c}{ Carga fatorial* $^{*}$} \\
\hline pH & 0,70 & 0,62 & $-0,15$ \\
\hline Areia & 0,38 & $-0,41$ & $-0,68$ \\
\hline Argila & $-0,50$ & 0,39 & 0,67 \\
\hline FeD & $-0,72$ & $-0,38$ & 0,39 \\
\hline MnD & $-0,26$ & $-0,85$ & $-0,07$ \\
\hline ZnD & $-0,54$ & 0,55 & $-0,03$ \\
\hline CuD & $-0,71$ & $-0,16$ & $-0,46$ \\
\hline NiD & 0,05 & $-0,35$ & $-0,54$ \\
\hline CdD & $-0,37$ & 0,77 & $-0,29$ \\
\hline PbD & $-0,22$ & 0,51 & $-0,60$ \\
\hline CrD & $-0,64$ & 0,30 & $-0,42$ \\
\hline Autovalor & 0,90 & 0,24 & 0,15 \\
\hline Variância total (\%) & 3,69 & 3,03 & 2,25 \\
\hline Variância & 30,76 & 25,28 & 18,76 \\
\hline acumulada (\%) & 30,76 & 56,04 & 74,80 \\
\hline Valor p & 0,001 & 0,001 & 0,001 \\
\hline Foramcon & & & \\
\hline
\end{tabular}

*Foram consideradas significativas as cargas fatoriais > 0,50.

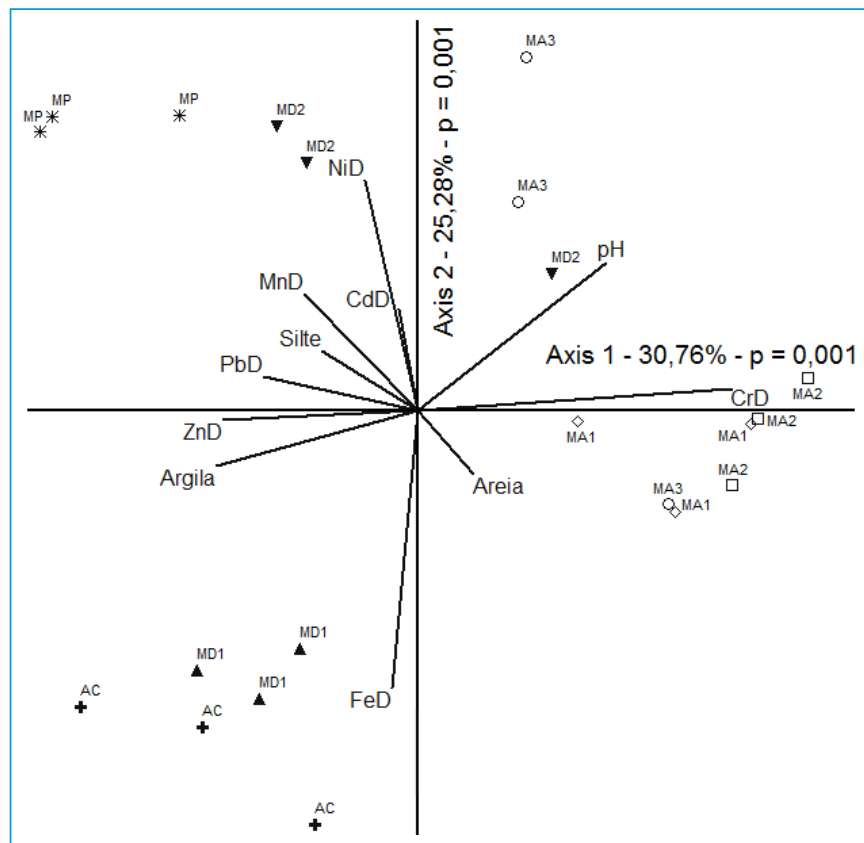

MP: mina em fase de pesquisa; MD1 e MD2: áreas da mina desativada Olho d’Água; MA1, MA2 e MA3: áreas da mina ativa Barra Verde; AC: área controle do solo.

Figura 5 - Análise de componentes principais (ACP) dos teores disponíveis dos metais pesados $\mathrm{Fe}, \mathrm{Mn}, \mathrm{Zn}, \mathrm{Cu}, \mathrm{Ni}, \mathrm{Cd}, \mathrm{Pb}$ e $\mathrm{Cr}$, do $\mathrm{pH}$ e dos teores de areia, argila e silte dos solos das áreas das minas Barra Verde e Olho d'Água e da área controle $(n=21)$. 
A contenção realizada por meio de barragens ou diques impede que o rejeito seja perdido por erosão e aporte elementos para o solo.

O rejeito pode também ser reprocessado no intuito de reaproveitar scheelita desperdiçada ou ainda ser reciclado. Enquanto houver a perspectiva de reaproveitamento da scheelita, o método de deposição do rejeito pode corresponder ao empilhamento drenado, cujo sistema de drenagem interna eficiente garante a estabilidade física das pilhas. Os rejeitos com formas de reaproveitamento esgotadas podem ser dispostos em aterros industriais, o que reduz o potencial de difusão dos metais pesados e o risco da conversão desses metais para formas mais disponíveis (BARROS et al., 2011).

Por fim, destaca-se a necessidade de empregar medidas que impeçam a disponibilização de metais pesados, além de empreender esforços para a aplicação de tecnologias de remediação viáveis, como a fitorremediação, em razão dos menores custos e do menor impacto ao ambiente (ANDRADE et al., 2009).

\section{CONCLUSÕES}

Os incrementos nos teores dos metais pesados decorrentes da exploração de scheelita na região tropical semiárida configuram cenários de contaminação ambiental em estágios similares nas minas ativa e desativada. Isso indica que, independentemente do tempo de exposição das pilhas de resíduos, as medidas de proteção e recuperação ambiental são essenciais para conter o aporte e a disponibilização de metais pesados.

Os teores de $\mathrm{Cd}, \mathrm{Cu}$ e $\mathrm{Pb}$ nas áreas mineradas estiveram acima dos valores de investigação agrícola estabelecidos pela legislação brasileira. Reconhecendo-se o risco à saúde humana, salienta-se a necessidade de adoção de medidas de remediação dessas áreas.

Implantar medidas de contenção e disposição final adequadas dos estéreis e rejeitos é necessário para reduzir o potencial de difusão da contaminação por metais pesados para as áreas adjacentes às minas em decorrência das erosões tanto eólica quanto hídrica durante os eventos chuvosos intermitentes característicos da região semiárida.

\section{REFERÊNCIAS}

ANDRADE, M.G.; MELO, V.F.; GABARDO, J.; SOUZA, L.C.P.; REISSMANN, C.B. (2009) Metais pesados em solos de área de mineração e metalurgia de chumbo: I - fitoextração. Revista Brasileira Ciência do Solo, v. 33, n. 6, p. 1879-1888. https://doi. org/10.1590/S0100-06832009000600037

ASSOCIAÇÃO BRASILEIRA DE NORMAS TÉCNICAS (ABNT). (2OO6) NBR 13028: elaboração e apresentação de projeto de barragens para disposição de rejeitos, contenção de sedimentos e reservação de água. São Paulo: Associação Brasileira de Normas Técnicas, 6 p.

BARROS, Y.J.; MELO, V.F.; KUMMER, L.; SOUZA, L.C.P.; AZEVEDO, J.C. (2011) Indicadores físicos e químicos de qualidade de solos deárea de mineração e metalurgia de chumbo. Semina: Ciências Agrárias, v. 32 , n. 4, p. 1385-1404. https://doi.org/10.5433/1679-0359.2011v32n4p1385

BIONDI, C.M.; NASCIMENTO, C.W.A.; FABRICIO NETA, A.B.; RIBEIRO, M.R. (2011) Teores de Fe, Mn, Zn, Cu, Ni e Co em solos de referência de Pernambuco. Revista Brasileira de Ciência do Solo, v. 35, n. 3, p. 1057-1066.

BRASIL. (2005) Conselho Nacional do Meio Ambiente. Resolução no 357, de 17 de março de 2005. Dispõe sobre a classificação dos corpos de água e diretrizes ambientais para o seu enquadramento, bem como estabelece as condições e padrões de lançamento de efluentes, e dá outras providências. Diário Oficial da União, n. 53, p. 58-63.

BRASIL. (2009) Conselho Nacional do Meio Ambiente. Resolução no 420, de 28 de dezembro de 2009. Dispõe sobre critérios e valores orientadores de qualidade do solo quanto à presença de substâncias químicas e estabelece diretrizes para o gerenciamento ambiental de áreas contaminadas por essas substâncias em decorrência de atividades antrópicas. Diário Oficial da União, n. 249, p. 81-84.
CAMPOS, M.C.C. (2010) Atributos dos solos e riscos de lixiviação de metais pesados em solos tropicais. Ambiência, v. 6, n. 3, p. 547-565.

DANTAS, J.R.A. (2000) Distritos Mineiros do Nordeste Oriental. In: DANTAS, J.R.A.; BARROS, L.B.; SOUZA, V.C; MONT'ALVERNE, A.A.F. (orgs.). Programa Nacional de Distritos Mineiros. Recife: DNPM $4^{\circ}$ Distrito. 90 p.

DAVIES, T.C.; MUNDALAMO, H.R. (2010) Environmental health impacts of dispersed mineralisation in South Africa. Journal of African Earth Sciences, v. 58, n. 4, p. 652-666. https://doi.org/10.1016/j.jafrearsci.2010.08.009

EMPRESA BRASILEIRA DE PESQUISA AGROPECUÁRIA (EMBRAPA). (1971) Levantamento Exploratório-Reconhecimento dos solos do Rio Grande do Norte. Recife: Convênio de Mapeamento de Solos MA/DNPEA-SUDENE/DRN. 536 p.

EMPRESA BRASILEIRA DE PESQUISA AGROPECUÁRIA (EMBRAPA) (1997) Manual de métodos de análise de solo. $2^{a}$ ed. Rio de Janeiro: EMBRAPA-CNPS. 212 p.

EMPRESA BRASILEIRA DE PESQUISA AGROPECUÁRIA (EMBRAPA) (1999) Manual de análises químicas de solos, plantas e fertilizantes. Brasilia: Embrapa Comunicação para Transferência de Tecnologia. 370 p.

EMPRESA BRASILEIRA DE PESQUISA AGROPECUÁRIA (EMBRAPA) (2013) Centro Nacional de Pesquisas de Solos. Sistema brasileiro de classificação de solos. 3. ed. Rio de Janeiro: EMBRAPA. 353 p.

GUO, G.L.; ZHOU, Q.X.; KOVAL, P.V;; BELOGOLOVA, G.A. (2006) Speciation distribution of $\mathrm{Cd}, \mathrm{Pb}, \mathrm{Cu}$, and $\mathrm{Zn}$ in contaminated Phaeozem in north-east China using single and sequential extraction procedures. Australian Journal of Soil Research, v. 44, n. 2. p. 135-142. https://doi.org/10.1071/SR05093 
KHALIL, A.; HANICH, L.; BANNARI, A.; ZOUHRI, L.; POURRET, O.; HAKKOU, R. (2013) Assessment of soil contamination around an abandoned mine in a semi-arid environment using geochemistry and geostatistics: Pre-work of geochemical process modeling with numerical models. Journal of Geochemical Exploration, v. 125, p. 117-129. https://doi.org/10.1016/j.gexplo.2012.11.018

KOTTEK, M.; GRIESER, J.; BECK, C.; RUDOLF, B.; RUBEL, F. (2006) World Map of the Köppen-Geiger climate classification updated. Meteorologische Zeitschrift, v. 15, n. 3, p. 259-263. https://doi. org/10.1127/0941-2948/2006/0130

LIU, H.; PROBST, A.; LIAO, B. (2005) Metal contamination of soils and crops affected by the Chenzhou lead/zinc mine spill (Hunan, China). Science of The Total Environment, v. 339, n. 1-3, p. 153-166. https://doi.org/10.1016/j.scitotenv.2004.07.030

MAIGA, A.; DIALLO, D.; BYE, R.; PAULSEN, B.S. (2005) Determination of some toxic and essential metal lons in medicinal and edible plants from Mali. Journal of Agricultural and Food Chemistry, v. 53, n. 6. p. 2316-2321. https://doi.org/10.1021/jfO40436o

MCCUNE, B.; MEFFORD, M.J. (2011) PC-ORD: Multivariate analysis of ecological data, version 6.O. MjM Software Design. Oregon.

MOURA, M.C.S.; LOPES, A.N.C:; MOITA, G.C.; MOITA NETO, J.M. (2006) Estudo multivariado de solos urbanos da cidade de Teresina. Química Nova, v. 29, n. 3, p. 429-435. https://doi.org/10.1590/S010040422006000300005

NAVARRO, M.C.; PÉREZ-SIRVENT, C:; MARTÍNEZ-SÁNCHEZ, M.J.; VIDAL, J.; TOVAR, P.J.; BECH, J. (2008) Abandoned mine sites as a source of contamination by heavy metals: a case study in a semiarid zone. Journal of Geochemical Exploration, v. 96, n. 2-3, p. 183193. https://doi.org/10.1016/j.gexplo.2007.04.011
PEAKALL, D.; BURGER, J. (2003) Methodologies for assessing exposure to metals: speciation, bioavailability of metals, and ecological host factors. Ecotoxicology and Environmental Safety, v. 56, n. 1, p. 110-121. https://doi.org/10.1016/S0147-6513(03)00055-1

PETTA, R.A.; SINDERN, S.; SOUZA, R.F.; CAMPOS, T.F.C. (2O14) Influence of mining activity on the downstream sediments of scheelite mines in Currais Novos (NE Brazil). Environmental Earth Sciences, v. 72, n. 6, p. 1843-1852. https://doi.org/10.1007/ s12665-014-3093-0

PRESTON, W.; NASCIMENTO, C.W.A.; BIONDI, C.M.; SOUZA JUNIOR, V.S.; SILVA, W.R.; FERREIRA, H.A. (2014) Valores de referência de qualidade para metais pesados em solo do Rio Grande do Norte. Revista Brasileira de Ciência do Solo, v. 38, n. 3, p. 1028-1037. https:// doi.org/10.1590/S0100-06832014000300035

PRUVOT, C.; DOUAY, F.; HERVÉ, F.; WATERLOT, C. (2006) Heavy metals in soil, crops and grass as a source of human exposure in the former mining areas. Journal of Soils and Sediments, v. 6, p. 215220. https://doi.org/10.1065/jss2006.10.186

RAZO, I.; CARRIZALES, L.; CASTRO, J.; DÍAZ-BARRIGA, F.; MONROY, M. (2004) Arsenic and heavy metal pollution of soil, water and sediments in a semi-arid climate mining area in Mexico. Water, Air, and Soil Pollution, v. 152, p. 129-152. https://doi.org/10.1023/ B:WATE.0000015350.14520.c1

SILVA, T.O;; MENEZES, R.S.C. (2010) Disponibilidade de micronutrientes catiônicos em solo arenoso após adubação orgânica. Revista Brasileira de Ciências Agrárias, v. 5, n. 3, p. 328-335.

UNITED STATES ENVIRONMENTAL PROTECTION AGENCY (USEPA). (1998) Microwave assisted acid digestion of sediments, sludges, soils, and oils: Method 3051A. USEPA. CD-ROM. 